\title{
Application of Customized Navigated Template for Percutaneous Radiofrequency Thermocoagulation Treatment of Primary Trigeminal Neuralgia
}

\author{
Peng Wang1,2, Tiebao Gu³, Zefeng Zhang2, Huiqun $\mathrm{Wu}^{4}$, Dafeng $\mathrm{Ji}^{5^{*}}$ \\ ${ }^{1}$ Department of Pediartic Orthopaedic, Nantong Rich Hospital Affiliated to Yangzhou University, Yangzhou, \\ China \\ 2Jiangsu ZhouKe Medical Instrument Technological Co., Ltd., Nantong, China \\ ${ }^{3}$ Department of Pain, Nantong Convalescence Hospital Affiliated to Nantong University, Nantong, China \\ ${ }^{4}$ Medical College Affiliated to Nantong University, Nantong, China \\ ${ }^{5}$ Digital Medical Center, Fudan University, Shanghai, China

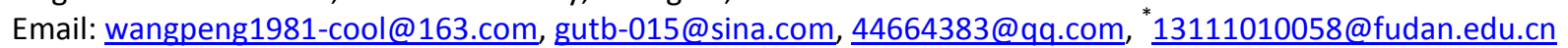

Received 17 July 2015; accepted 21 September 2015; published 24 September 2015

Copyright (C) 2015 by authors and Scientific Research Publishing Inc.

This work is licensed under the Creative Commons Attribution International License (CC BY).

http://creativecommons.org/licenses/by/4.0/

(c) (i) Open Access

\begin{abstract}
Objective: To investigate the successful rate and accuracy of percutaneous radiofrequency thermocoagulation (PRT) for treatment of primary trigeminal neuralgia (PTN) with customized navigated template via three dimensional (3D) printing technique. Methods: 65 patients with PTN were recruited from January 2014 to March 2015 and randomly divided into two groups: template group $(n=28)$ and traditional group $(n=37)$. The patients in traditional group received PRT under guidance of $\mathrm{C}$-arm fluoroscopy, while the ones in template group were treated with customized navigated templates. The data of time, depth and accuracy rate of puncture, the average effective dose equivalent of radiation, complications after operation were collected and analyzed. Results: No intra-operative failures occurred in the template group: the pain was alleviated immediately after operation. Accuracy rate of the template group was $100 \%$ while $96 \%$ was achieved in traditional group. However, the average time of puncture by the template was significantly reduced compared with traditional group $(2.37 \pm 0.64$ minutes and $24.2 \pm 6.55$ minutes, respectively; $P<0.001$ ). Meanwhile, the average effective dose equivalent of radiation was apparently reduced compared to the traditional group. The depth of puncture in operation was mostly close to the results of simulation $(9.45 \pm 0.58 \mathrm{~cm}$ and $9.33 \pm 0.87 \mathrm{~cm}$ respectively, $P>0.05)$. No complications were observed in template group while several complications such as blooding, leakage of cerebrospinal fluid and dizziness were observed in traditional group. Conclusion: The application of customized template is advocated for improving the accuracy of PRT.
\end{abstract}

${ }^{*}$ Corresponding author.

How to cite this paper: Wang, P., Gu, T.B., Zhang, Z.F., Wu, H.Q. and Ji, D.F. (2015) Application of Customized Navigated Template for Percutaneous Radiofrequency Thermocoagulation Treatment of Primary Trigeminal Neuralgia. Chinese Medicine, 6, 175-180. http://dx.doi.org/10.4236/cm.2015.63019 
Keywords

Primary Trigeminal Neuralgia, 3D Printing, Radiofrequency, Customized Template

\section{Introduction}

The primary trigeminal neuralgia (PTN) is a nerve disorder that causes a stabbing or electric-shock-like pain in parts of the face, which was first reported by Nicolas Andri in 1756 [1]. The pathogen of PTN is still unclear, while secondary TN is always a sequela of malformation, tumors or trauma in encephalic surgeries [2] [3].

At present, kinds of medicines and surgical operations have been utilized for the treatment of TN [3]-[9]. However, the results seem not to be completely satisfying. In many cases, drug resistant becomes more regularly and attacks become more and more resistant over time so that some patients cannot endure the side effects of high-dose medication and intolerably intense pain after clinical treatments. At last, a surgical procedure is necessary. Nonetheless, recurrence rate of pain after surgical operations is significantly high. Meanwhile, the good effects of surgical procedure depend on the experiences of surgeons and familiarities with variances of encephalic anatomy. Recently, the PRT caters for more patients' demands due to immediate pain relief, lower expense, minimal trauma and high efficacy [10]. However, several complications such as masticatory weakness, dysesthesia, and corneal numbness were also reported due to long procedure and high dose of radiation [11]. Thus, in order to promote the accuracy of PRT, various instruments such as computer temography, neuro-navigation were applied [12] [13]. But these applications are limited due to the price and unstable effects. Nevertheless, the ratio of pain relief was not as high as expected [14].

Nowadays, computer-aided surgery (CAS) has been more and more widespread and significant in the field of most surgeries [15]-[17], which could reduce risks and promote accuracy through preoperative simulation. Furthermore, more studies on 3D printing can make the ideas of CAS come true [18]-[21]. However, there is seldom applications in pain management been reported recently. The character of pain management is microtrauma, variance of anatomic structures, which fits the advantage of CAS and 3D printing techniques.

Thus, this study aims to design a novel method to increase the ratio of the management accuracy of pain surgery. We designed a customized navigated template with Computer-Aided Design (CAD) and 3D printing according to the patient specific anatomy. The results show that the customized navigated template increased the accuracy, and reduced the procedure and the dose of radiation of PRT.

\section{Patients and Methods}

\subsection{Patients}

The study was approved by local ethics committee at the Nantong Convalescence Hospital affiliated to Nantong University. Written informed consent was made for enrolled patients. As secondary TN being excluded, 65 outpatients from Jan 2014 to March 2015 were recruited and were divided randomly into two groups: the template group and traditional group.The patients in traditional group received PRT under guidance of C-arm fluoroscopy, while the ones in template group were treated with customized navigated templates combined with C-arm fluroscopy. Basic characteristics of the two groups were shown as Table 1.

\subsection{Surgical Procedures}

All patients were received thin slice CT scanning (SIMENS AVANTO Germany). Every slice is $0.625 \mathrm{~mm}$ thick. The scanning region is from top of the skull to maxillary. The imaging data was imported as Digital Imaging and Communications in Medicine (DICOM) files into Materialise's Interactive Medical Image Control System (MIMICS) 16.0 software (Materialise, Leuven, Belgium).

After image processing which contained thresh-holding and morphological operations, the model of encephalic and skin model were visualized (Figure 1), which were saved as Stereolithography (STL) files.

The diameter of foreman oval was measured (Figure 2(a)) and the best puncture path was simulated in 3-Matic software 8.0 (Materialise, Leuven, Belgium), meanwhile, the depth of puncture (from skin to foreman oval) was measured (Figure 2(b)). 


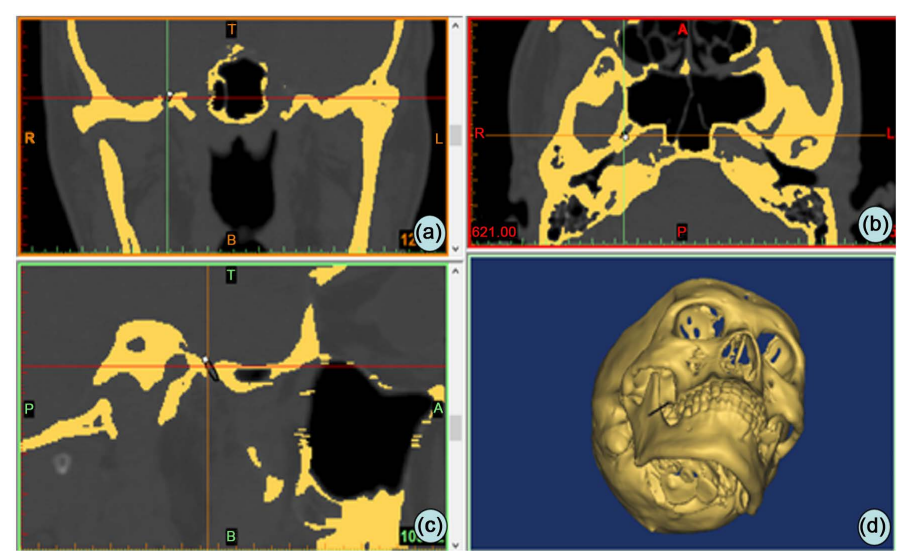

Figure 1. The DICOM data imported into MIMICS and mask of bone was threshold segmented ((a) coronal position; (b) axial position; (c) sagittal postion; (d) the reconstruction of bone).
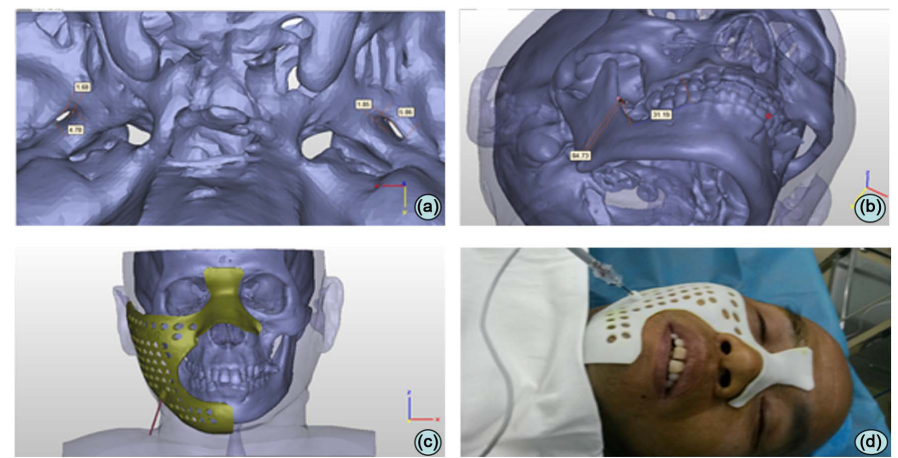

Figure 2. Model of the patient, morphology of foramen oval and digital template. (a) The morphology of foramen oval; (b) The optimum path of simulator punction; (c) the digital customized template; (d) the plate fit maxillofacial surface in operation.

Table 1. Basic characteristics comparison between two groups.

\begin{tabular}{|c|c|c|}
\hline & Template group $(\mathrm{N}=28)$ & Traditional group $(\mathrm{N}=37)$ \\
\hline Age & $56.4 \pm 12.7$ & $61.2 \pm 18.3$ \\
\hline \multicolumn{3}{|l|}{ Lateralization } \\
\hline right & 18 & 21 \\
\hline left & 8 & 15 \\
\hline bilateral & 2 & 1 \\
\hline \multicolumn{3}{|l|}{ Region of pain } \\
\hline V1 & 0 & 0 \\
\hline $\mathrm{V} 2$ & 8 & 11 \\
\hline V3 & 13 & 21 \\
\hline $\mathrm{V} 1+\mathrm{V} 2$ & 0 & 0 \\
\hline $\mathrm{V} 2+\mathrm{V} 3$ & 7 & 5 \\
\hline $\mathrm{V} 1+\mathrm{V} 3$ & 0 & 0 \\
\hline $\mathrm{V} 1+\mathrm{V} 2+\mathrm{V} 3$ & 0 & 0 \\
\hline
\end{tabular}


With application of reverse-engineering, the osteal characteristics of face such as zygomatic arch and nasal root were picked up and the digital customized navigated template was extruded $2 \mathrm{~mm}$ and trimmed the edges (Figure 2(c)), the needle way is designed according the path from skin to foremen oval. In the end, the digital template was fabricated from 3D printing machine (ZRapid, SLA300, China).The material of template is polylactic acid which is bio-compatible without any poisonous effect.

The patient was in supine position. The maxillofacial region was sterilized by iodophor and the template was sterilized by plasma. After the puncture region was locally anaesthetized, the template was put to fit the maxillofacial surface shape (Figure 2(d)). According to the depth of puncture in simulation, minimal adjust was made with the guidance of the C-arm fluoscopy. When the target pot was achieved, the pain was triggered. At the same time, the following PRT operations were performed as a matter of routine as soon as possible.

\subsection{Data Collection}

Time of surgical process, depth and accuracy of punture was measured; meanwhile, average effective dose equivalent of radiation was recorded with Radiation detector (LK3600, ReKo China).

\subsection{Statistical Analysis}

SPSS13.0 was utilized in this paper. Student's-t test was used for analysis. $P$ value less than 0.05 was considered to be statistically significant.

\section{Results}

1) Basic characteristics of two groups (Table 1).

2) The diameters of foramen ovale (Table 2).

3) The time of puncture and accuracy rate of operation and adverse reactions (Table 3).

4) The depth of puncture between simulation and real procedure (Table 4).

\section{Table 2. The difference of foramen ovale between two groups.}

\begin{tabular}{cccc}
\hline & & & \\
& & & Template group \\
Left & length & $7.13 \pm 2.46^{\text {ac }}$ & $6.28 \pm 1.67$ \\
& width & $3.46 \pm 2.58^{\text {bd }}$ & $2.73 \pm 3.16$ \\
\multirow{2}{*}{ Right } & length & $6.51 \pm 2.84$ & $7.72 \pm 2.19$ \\
& width & $2.93 \pm 2.55$ & $3.54 \pm 2.19$ \\
\hline
\end{tabular}

Note: a represents $P>0.05$, while left length between template group and traditional group; b represents $P>0.05$, while left width between template group and traditional group; c represents $P>0.05$, while length between left and right; d represents $P>0.05$, while width between left and right.

Table 3. The variance of time, accuracy rate, dose of radiation and adverse reactions of puncture.

\begin{tabular}{|c|c|c|}
\hline & Template group & Traditional group \\
\hline Time of puncture (min) & $2.1 \pm 1.2^{* *}$ & $20.2 \pm 8.6$ \\
\hline Total procedure time (min) & $30.5 \pm 4.6^{* *}$ & $62.3 \pm 10.4$ \\
\hline Accuracy rate (percent) & $100^{\#}$ & 96 \\
\hline Average effective dose equivalent of radiation (mSv) & $0.152 \pm 0.003^{* *}$ & $1.438 \pm 0.032$ \\
\hline \multicolumn{3}{|l|}{ Adverse reactions } \\
\hline blooding & 1 & 4 \\
\hline leakage of cerebrospinal fluid & 0 & 2 \\
\hline dizzness & 0 & 1 \\
\hline nausea & 0 & 0 \\
\hline vomit & 0 & 0 \\
\hline diplopia & 0 & 0 \\
\hline Cost (RMB) & $6538.4 \pm 38.7^{\#}$ & $6928.3 \pm 45.2$ \\
\hline
\end{tabular}

\footnotetext{
${ }^{* *} P<0.001 ;{ }^{\#} P>0.05$.
} 
Table 4. The depth of puncture between simulation and real procedure.

\begin{tabular}{ccc}
\hline & Simulation procedure & Real procedure \\
\hline Depth of puncture & $9.05 \pm 0.58^{*}$ & $9.55 \pm 0.83$ \\
\hline
\end{tabular}

${ }^{*} P>0.05$.

\section{Discussion}

This paper provides a new method to promote the accuracy of percutaneous punction and reduces the time of repeat puncture and radiation according to the CAS and 3D printing technique apparently.

The morphological variations of foramen ovale has been described in recent studies [22] [23], but most of them noted that there was no significantly difference between two sides. However, in this study, some foreman ovales had narrow morphology, and both sides were obviously asymmetry. During the simulation, traditional puncture path could hardly get the target pot successfully. Considering this, we moved the percutaneous puncture pot laterally so that the puncture path got the target successfully without any obstacle. In this case, the surgical process time was about $1 \mathrm{~min}$ and the routine was succeed with customized template.

Jen-Tsung Yang et al. suggested 3D reconstruction can improve the accuracy of puncture apparently [24]. However, it was necessary to adjust the tip of needle several times during operation. According to the articles [24] [25], the average time of procedure was about 20 minutes, whereas 1 to 2 minutes was spent in the template group. Moreover, the template can be stored for repetitive case. Meanwhile, several paths can be integrated in one template in case of failure from one path. In this study, a zygomatic path was finally selected and succeeded after the failure of foreman ovale path in a V2 case.

However, a patient with transient blooding appeared during the procedure, but the effect was satisfying. The authors consumed that the design of template was from the CT data, which was hardly to show soft tissue especially blood vessel. Osteal marks were only considered in this study while some important soft tissues have been ignored. This study was focused on improving the accuracy rate of PRT and reducing the dose of radiation, however, there was no significantly increase in the cost of discharge and simulation training.

\section{Conclusion}

The customized template can improve the accuracy of percutaneous puncture and reduce the dose of radiation for PTN.

\section{Acknowledgements}

Special thanks to the technical and administrative staff at Jiangsu ZhouKe Medical Instrument Technological Co., Ltd., thanks to Mr. Zefeng Zhang for excellent support in supplying equipment and Dr. Huiqun Wu in language management to facilitate this study.

\section{Declaration of Interest}

The authors received no financial support. However, no direct funding was received for this particular study.

\section{References}

[1] Andre, N.A. (1756) Observations Pratiques Sur Les Maladies de L’Uretre. Chez Delaguette, Imprimeur de College et de L’Academie Roy de Chir, Paris, 318-382.

[2] Gronseth, G., Cruccu, G., Alksne, J., Argoff, C., Brainin, M., Burchiel, K., et al. (2008) Practice Parameter: The Diagnostic Evaluation and Treatment of Trigeminal Neuralgia (An Evidence-Based Review): Report of the Quality Standards Subcommittee of the American Academy of Neurology and the European Federation of Neurological Societies. Neurology, 71, 1183-1190. http://dx.doi.org/10.1212/01.wnl.0000326598.83183.04

[3] Guo, Z., Ouyang, H. and Cheng, Z. (2011) Surgical Treatment of Parapontine Epidermoid Cysts Presenting with Trigeminal Neuralgia. Journal of Clinical Neuroscience, 18, 344-346. http://dx.doi.org/10.1016/j.jocn.2010.07.110

[4] Sindrup, S.H. and Jensen, T.S. (2002) Pharmacotherapy of Trigezminal Neuralgia. Clinical Journal of Pain, 18, $22-27$. http://dx.doi.org/10.1097/00002508-200201000-00004 
[5] Zakrzewska, J.M. and Linskey, M.E. (2014) Trigeminal Neuralgia. BMJ Clin Evid, pii: 1207. http://dx.doi.org/10.1136/bmj.g474

[6] Montano, N., Papacci, F., Cioni, B., Di Bonaventura, R. and Meglio, M. (2013) What Is the Best Treatment of DrugResistant Trigeminal Neuralgia in Patients Affected by Multiple Sclerosis? A Literature Analysis of Surgical Procedures. Clinical Neurology and Neurosurgery, 115, 567-572. http://dx.doi.org/10.1016/j.clineuro.2012.07.011

[7] Akram, H., Mirza, B., Kitchen, N. and Zakrzewska, J.M. (2013) Proposal for Evaluating the Quality of Reports of Surgical Interventions in the Treatment of Trigeminal Neuralgia: The Surgical Trigeminal Neuralgia Score. Neurosurgical Focus, 35, E3. http://dx.doi.org/10.3171/2013.6.FOCUS13213

[8] Gu, W. and Zhao, W. (2014) Microvascular Decompression for Recurrent Trigeminal Neuralgia. Journal of Clinical Neuroscience, 21, 1549-1553. http://dx.doi.org/10.1016/j.jocn.2013.11.042

[9] Oesman, C. and Mooij, J.J. (2011) Long-Term Follow-Up of Microvascular Decompression for Trigeminal Neuralgia. Skull Base, 21, 313-322. http://dx.doi.org/10.1055/s-0031-1284213

[10] Karol, E.A., Sanz, O.P., Gonzalez La Riva, F.N. and Rey, R.D. (1993) A Micrometric Multiple Electrode Array for the Exploration of Gasserian and Retrogasserian Trigeminal Fibers: Preliminary Report: Technical Note. Neurosurgery, 33, 154-158. http://dx.doi.org/10.1227/00006123-199307000-00027

[11] Smith, H.P., McWhorter, J.M. and Challa, V.R. (1981) Radiofrequency Neurolysis in a Clinical Model: Neuropathological Correlation. Journal of Neurosurgery, 55, 246-253. http://dx.doi.org/10.3171/jns.1981.55.2.0246

[12] Gusmão, S., Oliveira, M., Tazinaffo, U. and Honey, C.R. (2003) Percutaneous Trigeminal Nerve Radiofrequency Rhizotomy Guided by Computerized Tomography Fluoroscopy. Technical Note. Journal of Neurosurgery, 99, 785-786. http://dx.doi.org/10.3171/jns.2003.99.4.0785

[13] Xu, S.J., Zhang, W.H., Chen, T., Wu, C.Y. and Zhou, M.D. (2006) Neuronavigator-Guided Percutaneous Radiofrequency Thermocoagulation in the Treatment of Intractable Trigeminal Neuralgia. Chinese Medical Journal (English Edition), 119, 1528-1535.

[14] Erdine, S., Ozyalcin, N.S., Cimen, A., Celik, M., Talu, G.K. and Disci, R. (2007) Comparison of Pulsed Radiofrequency with Conventional Radiofrequency in the Treatment of Idiopathic Trigeminal Neuralgia. European Journal of Pain, 11, 309-313. http://dx.doi.org/10.1016/j.ejpain.2006.04.001

[15] Hirao, M., Ikemoto, S. and Tsuboi, H. (2014) Computer Assisted Planning and Custom-Made Surgical Guide for Malunited Pronation Deformity after First Metatarsophalangeal Joint Arthrodesis in Rheumatoid Arthritis: A Case Report. Computer Aided Surgery, 19, 13-19. http://dx.doi.org/10.3109/10929088.2014.885992

[16] Raaijmaakers, M., Gelaude, F., De Smedt, K., Clijmans, T., Dille, J. and Mulier, M. (2010) A Custom-Made GuideWire Positioning Device for Hip Surface Replacement Arthroplasty: Description and First Results. BMC Musculoskeletal Disorders, 11, 161. http://dx.doi.org/10.1186/1471-2474-11-161

[17] Modabber, A., Ayoub, N., Möhlhenrich, S.C., Goloborodko, E., Sönmez, T.T., Ghassemi, M., et al. (2014) The Accuracy of Computer-Assisted Primary Mandibular Reconstruction with Vascularized Bone Flaps: Iliac Crest Bone Flap versus Osteomyocutaneous Fibula Flap. Medical Devices: Evidence and Research, 7, 211-217. http://dx.doi.org/10.2147/MDER.S62698

[18] Liu, Y.F., Xu, L.W., Zhu, H.Y., Liu, S.-Y.S. (2014) Technical Procedures for Template-Guided Surgery for Mandibular Reconstruction Based on Digital Design and Manufacturing. BioMedical Engineering OnLine, 13, 63. http://dx.doi.org/10.1186/1475-925X-13-63

[19] Farzadi, A., Solati-Hashjin, M. and Asadi-Eydivand, M. (2014) Effect of Layer Thickness and Printing Orientation on Mechanical Properties and Dimensional Accuracy of 3D Printed Porous Samples for Bone Tissue Engineering. PLoS ONE, 9, e108252. http://dx.doi.org/10.1371/journal.pone.0108252

[20] Ventola, C.L. (2014) Medical Applications for 3D Printing: Current and Projected Uses. Pharmacy and Therapeutics, 39, 704-711.

[21] Parthasarathy, J. (2014) 3D Modeling, Custom Implants and Its Future Perspectives in Craniofacial Surgery. Annals of Maxillofacial Surgery, 4, 9-18. http://dx.doi.org/10.4103/2231-0746.133065

[22] Patil, J., Kumar, N., KG, M.R., Ravindra, S.S., SN, S., Nayak, B.S., et al. (2013) The Foramen Ovale Morphometry of Sphenoid Bone in South Indian Population. Journal of Clinical and Diagnostic Research, 7, 2668-2670.

[23] Khairnar, K.B. and Bhusari, P.A. (2013) An Anatomical Study on the Foramen Ovale and the Foramen Spinosum. Journal of Clinical and Diagnostic Research, 7, 427-429. http://dx.doi.org/10.7860/jcdr/2013/4894.2790

[24] Yang, J.T., Lin, M., Lee, M.H., Weng, H.H. and Liao, H.H. (2010) Percutaneous Trigeminal Nerve Radiofrequency Rhizotomy Guided by Computerized Tomography with Three-Dimensional Image Reconstruction. Chang Gung Medical Journal, 33, 679-683.

[25] Luo, F., Shen, Y., Wang, T., Meng, L., Yu, X.T. and Ji, N. (2014) 3D CT-Guided Pulsed Radiofrequency Treatment for Trigeminal Neuralgia. Pain Practice, 14, 16-21. http://dx.doi.org/10.1111/papr.12041 